This is the submitted version of the article:

ROCA, David, TENA, Daniel, LAZÀRO, Patricia, GONZÁLEZ, Alfonso, 2016. Is there gender bias when creative directors judge advertising? Name cue effect in ad evaluation. International Journal of Advertising. Vol. 35, no. 6, p. 1008-1023

DOI $\underline{10.1080 / 02650487.2015 .1128868}$

This version is available at https://ddd.uab.cat/record/189373- Users should check here the license of this document 
not for review

\section{IS THERE GENDER BIAS WHEN CREATIVE DIRECTORS JUDGE ADVERTISING? NAME CUE EFFECT IN AD EVALUATION}

Dr. David Roca, Universitat Autònoma de Barcelona, Spain

Dr. Daniel Tena, Universitat Autònoma de Barcelona, Spain

Dra. Patrícia Làzaro, Universitat Autònoma de Barcelona, Spain

Dr. Alfonso González, Universitat Autònoma de Barcelona, Spain

Dr. David Roca, Universitat Autònoma de Barcelona, Campus UAB, Bellaterra 08193 (Spain), david.roca@uab.cat, (34) 935814459

Dr. Daniel Tena, Universitat Autònoma de Barcelona, Campus UAB, Bellaterra 08193

(Spain), daniel.tena@uab.cat, (34)935814458

Dr. Patrícia Làzaro, Universitat Autònoma de Barcelona, Campus UAB, Bellaterra 08193

(Spain), patricia.lazaro@uab.cat, (34) 935814459

Dr. Alfonso González, Universitat Autònoma de Barcelona, Campus UAB, Bellaterra 08193

(Spain), alfons.gonzalez@uab.cat, (34) 935811541

The authors gratefully acknowledge the Ministerio de Economía y Competitividad (The Spanish Ministry of Economy and Competitivity) for funding this research: Edu Bonet for database work, Olivier Grau for statistical input, Bradley James Wilson for his wise advice in the last revision of the paper, Linda Charlesworth for text editing, and Saraí Meléndez for her tips. 


\title{
IS THERE GENDER BIAS WHEN CREATIVE DIRECTORS JUDGE ADVERTISING? NAME CUE EFFECT IN AD EVALUATION
}

\begin{abstract}
A lack of women in creative departments has been documented in previous research. These departments are seen as a male fraternity subculture in advertising agencies, where women experience many difficulties in their career progress. One of these drawbacks is gender bias in the selection of ideas' process. Male creative directors are believed to promote ideas created by men within a homosocial environment. This female perception, that emerged from previous qualitative research, is studied experimentally for the first time. Almost 90 advertising creative directors and higher level positions, assessed ads created by students in an advertising university course. In the current study we explore the effects of ad gender authorship. Results revealed an absence of gender bias based on ad name cues, neither the gender of the ad creators nor the creatives affected the evaluations. The findings are discussed and future research is proposed.
\end{abstract}

\section{INTRODUCTION}

Canary and Hause (1993) wrote an article based on a meta-analysis methodology entitled, "Is there any reason to research sex differences in communications?" Their paper concluded that sex effects are negligible but encouraged the development of new practices to find them. This inquiry satisfies this purpose and also resonates with recent calls from "women's perspective" studies to go deeper into the research of gender and creative departments (Mallia 2009; Grow 
et. al 2011; Mallia \& Windels 2011) and specifically in "the effect gender bias can have on the output and evaluation of women's creative work" (Windels \& Lee 2012, p. 504). This research aims to investigate gender differences in the advertising creation process, specifically in the evaluation stage, to discover if there is gender bias when male professionals working in advertising agencies select ideas. Due to the complexity of gender bias research, this paper will only focus on name cues (male, female or unknown) shown on the ads. Other related factors will not be addressed in this experimental design. Previous qualitative research suggests that professional women feel their ideas are discriminated against by men in advertising agencies (Grow et al. 2011; Windels \& Lee 2012). On the other hand, Hernández et al. (2012) argue that there is no relationship between a predominant creative male environment (Nixon 2003; Grow \& Broyles 2011) and advertising sexism, despite the broad use of gender stereotypes in advertising (Shao et al. 2014). In the same vein, Roca et al. (2013) gave voice to male creatives. Results show they do not perceive equality as a problem and feel discrimination is determined by a historically male chauvinistic society and not by creative department dynamics.

The main objective of this paper is to study if there is an unconscious bias towards advertising ideas from junior women. This can be understood as the hiring homogeneity that jeopardizes the minority which is women (Mallia 2009). Previous research regarding bias in the hiring processes in advertising has been studied by Sego (1999) in the account area and by Windels \& Lee (2012) and Roca et al. (2012) in the creative field. All three investigations used students as judges. The topic of gender bias on ad ideas has never been studied experimentally with advertising professionals to date. A new element is the use of creative 
practitioners as evaluators of ads, as done in previous literature related to advertising creativity evaluation (Koslow et al. 2003, Sasser \& Koslow 2008). Having the opinions of authentic creatives is very important, since young newcomers applying for entry levels positions in creative departments, are judged by their creative portfolio (Slayden et al. 1998; McLeod 2011) and not by university grades, selling experience or recommendation letters, as is the case within other departments and industries.

Some articles present extensive research regarding relationships among professionals in creative departments (Gelade 1997; Hackley 2003; Nixon 2003; Chong 2006; Hackley \& Kover 2007; Stuhlfaut 2011), factors that have an effect on advertising creativity (Sasser \& Koslow 2013), ad evaluations for awards (Kilgour et al. 2013), and by consumers (Rosengren et al. 2013), and effects of advertising creativity (Dáhlen et al. 2008). However, little attention has been dedicated to gender influences on ad evaluation (Roca et al. 2012). This research is a new step towards studying gender bias during the selection of creative ads using experimental methodology with practitioners, as globally framed in Csikszentmihalyi's systems model of creativity (1999). Transferred to the advertising domain, creative directors are the gatekeepers who allow newcomers to belong and progress in this field. If we refer to advertising creative outcomes, could gender be considered a barrier?

Literature suggests that women dominate advertising programs (Weisberg \& Robbs 1997; Mallia 2008; Fullerton et al. 2009) and account departments (Klein 2000, Pueyo 2010). The number of male and female students is equal in portfolio schools (Grow et al. 2011). However, the presence of women is limited in the creative departments of several western 
countries - Peru, Spain, Sweden, United Kingdom, and the USA- due to various factors (Weisberg \& Robbs 1997; Alvesson 1998; Kelly 2000; Martín-Laguno et al. 2007; Pueyo 2010; Grow \& Broyles 2011; Hernández et al. 2012, Mensa \& Grow 2015). Creative departments are considered as being a laddish creative environment, or what has been defined as men's club (Alvesson 1998; Nixon \& Crewe 2004; Broyles \& Grow 2008; Etayo \& Del Río 2008; Fitzsimmons 2008; Mallia 2009; Gregory 2009). One of the reasons is male networking outside the agency (Ibarra 1992; Gregory 2009) which leads, for example, to male dominance in judgment committees (Grow\& Broyles 2011; Roca, et al. 2011; Windels \& Lee 2012). Women lack peer recognition since they do not participate in such networks (Cuneo \& Petrecca 1997; Bosman 2005). In contrast, they appear to be trapped as pink ghetto, especially when limited to working on female products such as those, related with beauty, cleaning and children (Roca \& Pueyo 2011; Windels \& Lee 2012). Some other variables show that an absence of women in creative departments is related to managerial knowledge (Martín et al. 2009), lower salaries in the advertising industry for women (Martín 2007), a lack of creative leadership positions (Pool 2001; Mallia 2009) and, especially, motherhood penalty (Mallia 2009; Grow \& Broyles 2011), which is not exclusive to the advertising sector (e.g. Correll et al. 2007). Industry interest to highlight the lack of women in creative departments is growing. Recently, several books by female practitioners have appeared: Seducing the Boys Club: Uncensored Tactics from a Woman at the Top (Di Sesa 2008); Mad Women: A herstory of advertising (Knight \& Thorsell 2012); and Mad Women: The Other Side of Life on Madison Avenue in the '60s and Beyond (Mass 2013). Furthermore, the web page www.3percentconf.com developed by creative director Kate Gordon, points out that there is a lack of women in creative departments. 
Thus, the question to answer is whether creative author gender influences the selection of best ideas and if creators experience unconscious bias and are, therefore, gender biased. Our research question is tested in an experimental study where creative directors evaluated students' ads where gender was visible for the evaluators by means of a perception test.

\section{LITERATURE REVIEW}

Considering a gender perspective, the homosociability theory (1977), the similarity attraction theory (1961) and the gender bias paradigm (1968) provide a framework for this article.

\section{Homosociability theory}

Similarity plays a big role in homosociability. This can be defined as the "non sexual attraction held by men for members of their own sex" without erotic attraction (Bird 1996, p.121). This area of research started with Lipman-Blumen (1976) and Kanter (1977). The former introduced the concept "homosociality" as a form of occupational segregation of women, where men are attracted to and interested in other men as a way of keeping the high level hierarchies, building what is known as men's club or "old boy network". The latter proposed the concept "homosociability", and explained the disadvantages for women of being in low proportion in skewed groups in organizations. Kanter named the phenomena "tokenism": people are identified by ascribed characteristics such as sex, and a set of assumptions concerning culture, status and behavior. The approach to this theory in advertising has been developed mainly through qualitative methodology as now detailed. Homosociability was found in the construction of multiple networks, where men get better 
returns that women reinforcing gender inequalities (Ibarra 1992). These networks lead to two kinds of gender segregation (Grow \& Deng 2014); vertical, when there are fewer women in senior positions (creative directors), and horizontal, with male domination within creative departments. Windels and Lee (2012) researched the construction of gender and creativity in advertising departments through female voices. They found gender had a strong negative impact in creative's ideas evaluation, credibility and quality of assignments. Their results were consistent with previous qualitative research where creative women were the informants (Mallia 2009; Grow \& Broyles 2011; Grow et al. 2012). From these accounts, women's ideas are considered less valuable to male creative directors, who award more merit to men's ideas, to the detriment of creative quality, and indirectly women. However, when men are interviewed gender is not considered a key factor in the choosing of ideas (Roca et al. 2013).

\section{Theory of similarity}

The theory of similarity is also known as the similarity attraction paradigm, similar-to-me effect, similarity effect or law of attraction (Michinov \& Michinov 2011). This theory states that there is a strong relationship between interpersonal similarity and attraction (Byrne 1997). Perceived similarity has been studied through different dimensions which are likely to play a key role in attraction judgments, be it in love or recruitment processes. A meta-analysis conducted by Montoya et al. (2008) studied 313 laboratory and field investigations in this topic. The similarity effect, used by the vast majority of studies, was operationalized as attitudes and personality traits, refusing to study other types of similarity. After their research, they concluded that: "similarity leads to attraction in the laboratory setting" (p.907), when 
there is no previous interaction. However, results are not so clear in field studies with existing relationships.

The body of research related to recruiters' interpersonal attraction started with the Byrne's model in industrial-organization research in 1961. He suggested that "when applicants present biographically similar information to a white middle-class interviewer, ratings of job suitability, intelligence, personal attributes, and attraction of candidate are increased" (cited in Rand \& Wexley 1975, p.541). In this area, these kinds of findings have been mainly developed with interviews through laboratory (simulated interview technique) or field experiments (real-life interviews). Orphen (1984) employed real-life selection interviews in four insurance companies. He discovered that actual and perceived similarity based on attitude scales was fairly strongly related to both attraction and the decision to accept candidates for these jobs. Rand and Wexley (1975) observed this phenomenon generally occurs regardless of the race of the applicant or the level of racial prejudice of interviewers, and similar attitudes are more important for the hiring process. Considering previous research, the question arises as to whether gender similarity is a key factor in recruitment. Graves and Powell $(1988,1995)$ examined the direct and indirect effects on applicant sex on real campus interview outcomes and tested whether the similarity-attraction paradigm mediated these effects, but their results revealed no significant effects of applicant sex on interview outcomes; for male recruiters, interview outcomes were not affected by sex similarity. These results did not lead to similarity bias, and consequently there is a need to look into the research undertaken using the gender bias paradigm (Goldberg 1968). In this paradigm, judges don't have any information of applicants; they just judge creative outcomes. 


\section{Gender bias paradigm}

Prejudice against women can be generally examined with two kinds of studies. Firstly, assessing attitudes toward some groups (e.g. women), by getting conscious answers through qualitative methods as described previously (Mallia 2009; Grow et al. 2011; Windels \& Lee 2012, Roca et al. 2013) and by means of quantitative ones. In both cases, respondents are aware of examined attitudes towards gender. One survey (Hartman 1988) states that creative directors think they don't discriminate between men and women. Secondly, conducting studies with less information than that occurring in real sets where respondents are not aware that gender biases are being examined (unconscious answers). This methodology uses unobtrusive measures and usually employs student samples rather than engaging professional samples. These studies evaluate gender bias with respect to articles (Paludi \& Bauer 1983, Levenson et al. 1975), paintings (Ward 1979), job applications (Halon \& Cole 1975), resumes (Bosak \& Sczesny 2008), etc. Surprisingly, only three articles are related with advertising (Sego 1999, Windels et al. 2010, Roca et al. 2012).

Goldberg (1968) was the first to experiment the concept of unconscious gender bias by changing the authors' names in academic articles. He tried to discover if women were prejudiced against women. Results of this research are known as the "Goldberg paradigm." His experiment assessed students' perceptions regarding six academic articles from various professional backgrounds written supposedly by men as well as women. The results indicated that identical articles signed by men were better evaluated, although bias against women's work was significant only for the two articles in traditionally masculine fields as city planning and law (gender incongruity) and one in a neutral field (linguistics). Women 
assessed women worse than men, even for feminine fields. Swim et al. (1989) conducted a meta-analysis of 123 "real world" settings using students. They reported hardly any gender bias related with the articles. Only a slight effect was observed when the work being judged consisted of a masculine domain. Eagly et al. (1992) drew conclusions from meta-analysis of studies regarding gender effects on evaluation of leaders. It was found that female leaders were evaluated slightly less favorably compared to males, particularly for stereotypical masculine styles. Earlier, Olian et al. (1988) examined job applications and found a considerable tendency for men to fare better than women $(\mathrm{d}=0.41)$, but almost $80 \%$ of studies were based on 'male-type' positions.

The first investigation on gender bias in advertising was conducted much later than Goldberg's. Sego (1999) researched whether advertising professionals have negative beliefs when hiring women and black people in a laboratory setting. Results showed that sexist stereotypes did not modify the evaluations for advertising candidates in account services. Furthermore, the interaction of feminist beliefs and candidate sex were not significant. Male candidates were evaluated a little better than females. Windels et al. (2010) examined students' perceptions regarding gender norms associated with creative departments of advertising agencies. The experiment constituted an evaluation of fictitious text-based resumes from students for the position of creative director in the creative department of a student-run advertising agency. Gender perceptions did not influence decision-making when choosing a creative director for a student-run agency. A creative portfolio is, undoubtedly, a fundamental tool in accessing creative departments. Roca et al. (2012) researched gender bias when selecting creative ads in experimental conditions. They used advertising students as 
creators and about 800 undergraduate advertising students as judges of print ads created by the former group. Neither the gender of advertisement creators nor the judges affected the evaluations. These studies research gender bias in the hiring process in advertising, but none used practitioners as experimental subjects to judge creativity. The aim of this study is to present a closer perspective to reality introducing creative directors' evaluations.

\section{HYPOTHESES}

"Male-dominated jobs are thought to require characteristics stereotypically ascribed to men" (Eagly \& Mladinic 1994, p. 2). Advertising creative departments are traditionally considered a masculine domain that impedes progress and job satisfaction for women (Windels \& Lee 2012). Grow et al. (2011, p. 217) wrote in a cross-cultural qualitative study: "Both Spanish and American women suggest that the Big Ideas of male creatives are often prioritized". This study explores if gender bias is not only a female perception but also occurs in lab conditions. A real portfolio exercise was simulated based on this assumption. We analyze the influence of ad authorship on the professional appraisal of the level of creativity in print ads. Three hypotheses were established to measure gender bias name cues related with the evaluation of a creative portfolio in advertising.

$\mathrm{H}_{1}$ Male authorship increases the probability of recommending the selection of an ad compared to female authorship of ads.

$\mathrm{H}_{2}$ Male authorship increases the probability of recommending the selection of an ad compared to female authorship of ads when the creativity of the ad is taken into account (interaction effect) 
$\mathrm{H}_{3}$ Male authorship increases the probability of recommending the selection of an ad compared to female authorship of ads when the creative director's gender is taken into account.

\section{METHODS}

This research aims to verify the extent to which there is gender bias based on name cues when creative directors judge ads. As a result an experimental design was selected where the independent variable was gender authorship of the ad. In contrast to previous studies, samples were practitioners working in creative departments in top advertising agencies, as opposed to students. Creative directors were selected from Spanish advertising agencies.

\section{Participants sample and procedure}

Names of advertising agencies were obtained from three different sources: Infoadex, a Spanish advertising database; Independent Agencies Association; and finally, a special issue of the magazine El Publicista (Revista Especial Agencias de Publicidad y Medios 2013). The final pool had 70 advertising agencies based in Spain, including mainstream (31) and creative hotshops (39). In the end, 45 agencies took part in the study. Data from a total of 87 creative directors including top positions (Executive Creative Director, General Creative Director...) was used for the study. This is a pleasing number considering the difficulty in reaching this population and the market size of Spain (10,406.3 million euros in 2013, Estudio Infoadex 2014). Professionals who had never taken part in new talent selection processes were discarded, and copywriters and art directors, as well. Most of the professionals were aged between 35 and 44 years old (56.3\%). According to our sample data, $83.9 \%$ were male 
creatives $(n=73)$ and $16.1 \%$ were female creatives $(n=14)$. These figures coincide with previous studies of the advertising creative population in Spain (Martín 2007, Roca et al. 2011). The sample was taken from Barcelona (45.2\%) and Madrid (54.8\%) since these cities represent $90 \%$ of the advertising business in Spain. The experimental test was available online from November 2013 to February 2014. The experiment could be completed on line in less than 15 minutes.

\section{Ad sample and manipulation}

In order to increase external validity (confidence in the generalizability) of the research, print ads were obtained from university students on a creativity course in their final years of advertising studies. They created and designed a print ad for a local winery to be included in their portfolio. Prior to the experiment, creativity professors selected the most creative ads based on criteria called "subjective creativity" established in previous literature (Koslow et al. 2003). The measure defines a "creative" advertisement as one that is "both original and appropriate" (Sasser et al. 2013, p. 2). This first pool contained 29 print ads. In a second stage, 6 senior creatives, known by the researchers, rated the ads online based on a short creative brief. To reduce possible confound effects caused by screen variations, all ads were displayed in black and white. The final pool had the 9 most creative ads. Names and surnames of the authors were added and manipulated to present three variations, as used in previous literature: male (eg. Ángel Lázaro), female (eg. Ángela Lázaro), and first name initial (in order to avoid gender identification), expressed in this article as unknown gender, (eg. A. Lázaro). In contrast to English, Spanish enables the delimitation of the gender of a name, so manipulation check was not necessary in this case. The resulting factorial design 
had a total of 27 combinations ( 3 gender authorship x 9 ads). The participants were randomly assigned to one of the 3 sets to guarantee internal validity. Nine different ads, with their authorship, appeared randomly in each one (see figure 1 and 2). All participants evaluated the same nine ads but with a different name variation. The names used in the experiment were taken from previous research (Roca et al. 2012) in order to avoid Kasof's bias (1993), which states that female names are usually less attractive than those of males, when minimal information is shown in gender-bias researches.

(Place table 1 around here)

\section{Measures}

The administration of the stimuli consisted of five parts. The first part involved the presentation and general instructions. Creatives were told they formed part of an experiment which consisted in evaluating the level of creativity in students' ads applying for an entry level position. The second part entailed the asking of demographic questions in order to know the profile of the respondents. In the third section, the experiment was explained. Following a short creative brief, participants were asked to "evaluate the creative quality of the ads" according to their own criteria, based on the Consensual Assessment Technique (CAT, see Amabile 1982, 1996; Baer et al. 2004). To ensure validity of the instrument they were aware of authorship of the ad, because they had to type the name and surname of the author before evaluating. They could not continue the test without doing this step. Those ads where names were not well typed were not taken into account for the research.

(Place figure 1 and 2 around here)

Participants evaluated creativity of 9 different ads based on the following dichotomous question (as recommended by Rossiter 2011), "Would you recommend a student select this ad 
for their portfolio if they were looking for a creative job position?" Later, they had to evaluate each ad on an interval scale of 0 to 10 , with 10 representing the highest value in creativity and 0 the lowest (this scale is broadly known in Spain because is used in school grading). At the end of the experiment, respondents were thanked for their collaboration in the research. They were never told that gender bias based on authorship was being tested in order to avoid this information being passed on to the other practitioners. All tests were done on line through Parc (www.parc-online.es). This Spanish web based tool, similar to Qualtrix, allows the simultaneous viewing of stimuli and questions (Lázaro et al. 2014).

\section{FINDINGS}

We conducted a randomized block design with nine ads and three different authorships (male, female, unknown gender). Each participant evaluated nine ads where the authorship was randomly assigned. The order of the ads was rotated. The reliability of the portfolio was evaluated using Cronbach's alpha $(\alpha=0.87)$. To test $\mathrm{H}_{1}$ two models were adjusted : a) A logistic regression model to analyze the variable "Recommend the selection of an ad as a part of a junior portfolio" (yes or no). Ad gender authorship and their interaction were included as covariates, and the creative director as a random effect to take into account for repeated measures. b) A linear regression model to analyze the variable "Score of a 0-10 scale", considering the same factors defined in the previous model. The analyses were carried out using the procedure PROC GLIMMIX of SAS version 9.3 (SAS Institute Inc., Cary, NC, USA). Contrary to that hypothesized $\left(\mathrm{H}_{1}\right)$, male authorship did not increase the probabilities of recommending the selection of an ad compared to female authorship of ads $\left(M_{\text {mean }}=20 \%\right.$, $\left.F_{\text {mean }}=26 \%, U_{\text {mean }}=23 \% ; \mathrm{F}=0.99 ; \mathrm{p}=0.37\right)$. The interaction between ad creativity and gender 
authorship was neither found statistically significant $(\mathrm{F}=0.91 ; \mathrm{p}=0.56)$. Results of the estimated probabilities of recommending the selection of an ad depending on the gender who signs the authorship of the ad (male, female, unknown gender) are presented in Table 2. Although no statistically significant differences were found we may see some if we check authorship one by one (sometimes in favor of male names, sometimes in favor of female names). The biggest differences are found with the surname "Campos", but when performing pairwise comparisons, no statistically significant differences were found after applying Tukey's correction.

Similar results were obtained from the analysis of the quantitative response variable (score of 0-10 interval scale), and it confirmed that gender authorship did not affect the evaluation $\left(\mathrm{M}_{\text {mean }}=3.29, \mathrm{~F}_{\text {mean }}=3.45, \mathrm{U}_{\text {mean }}=3.38 ; \mathrm{F}=0.82 ; \mathrm{p}=0.44\right)$. The interaction results $(\mathrm{F}=1.01$; $\mathrm{p}=0.44$ ) are presented in Table 3 .

(Insert table 2 and 3 around here)

$\mathrm{H}_{2}$ stated that "Male authorship increases the probability of recommending the selection of an ad compared to female authorship of ads when the creativity of the ad is taken into account" (interaction effect). The creativity level of ads was based on the question "Which is the best ad you have seen?" Lazaro and Hinojo's ads were recommended by $32 \%$ and $25 \%$ of the creative directors respectively. The recommendation of the rest of the ads did not reach $8 \%$. To check $\mathrm{H}_{2}$, the interaction between creativity of the ad and gender authorship was included in the logistic regression model. No statistically significant differences were found $(F=0.30$, $p=0.74$ ). Gender name cues did not influence the evaluations (see Table 4). Therefore the findings did not support either $\mathrm{H}_{1}$ or $\mathrm{H}_{2}$, and hence demonstrate that gender is not a key factor 
in evaluating advertising creativity under lab conditions when taking into account the name cues of the author.

(Insert table 4 around here)

Finally, in order to check $\mathrm{H}_{3}$, "Male authorship increases the probability of recommending the selection of an ad compared to female authorship of ads when the creative director's gender is taken into account.", the interaction between gender of the creative director and authorship gender was included in the logistic regression model. No differences were found between these two variables $(\mathrm{F}=1.4 ; \mathrm{p}=0.25)$. In contrast to the claim, the probability of recommending the selection of an ad does not depend on the gender of the creative director. The data obtained depicts that unconscious bias, based on name cues, does not prevail either in male or in female creative directors when they evaluate ads of a junior portfolio created by future advertising professionals (see Table 5).

(Insert table 5 around here)

\section{DISCUSSION}

Gender bias in creative departments is a multifactorial topic. This research did not aim to give an answer to this phenomenon as a whole. The purpose of this study was to evaluate one factor of gender bias through an experiment, where 87 creative directors assessed print ads for a student's portfolio with different gender authorships. Thus, it is the first time this topic is investigated with this methodology with advertising creative directors, and contributes to the progress in gender and management research (see Broadbridge \& Simpson 2011).

A portfolio is essential for young advertising students to access creative careers (McLeod $e t$ al. 2011). Gender bias was evaluated through the factor of authorship (female, male and 
unknown gender). For the first time in academic literature, a sample composed of advertising creative practitioners was used for this purpose. Although creative departments are highly male dominated, the results of this study reveal that there is no gender bias with respect to the evaluation of the ads, considering the variable of gender authorship through name cues. Findings show that gender authorship of the ad was not a determining factor in recommending its selection for the student's portfolio, even when high creativity ads were studied separately. Creative advertising professionals, both men and women value ads equally, regardless of the gender of the author. Theories of homosociability (Lipman-Blumen 1976, Kanter 1977), similarity (see overview in Byrne 1997) and the Goldberg paradigm (1968) were not confirmed through our experiment set. Results show no pro-male bias of men in the evaluation of the work, and are congruent with earlier research regarding creativity in other fields (Kaufman et al. 2010) and advertising assessment of gender bias using students as judges (Sego 1999, Windels et al. 2010, Roca et al. 2012). They are also very similar to the results of the gender-bias research in other fields using name cues (Olian et al. 1988, Swim et al. 1989, and Eagly et al. 1992). This is particularly significant in Spain, where culture is considered more male oriented than in other western countries (Grow et al. 2011). If Windels et al. (2010, p.22) found that "boys' club culture does not start in the classroom", following this research we could suggest this biased culture, also does not start in creatives' minds as isolated individuals when they judge ads, and it appears to be born in the social dynamics of the creative departments themselves or other factors different to name cues studied here. Results complement previous research based on the social construction of creativity (e.g. Grow et al. 2011, Windels \& Lee 2012), where women felt their ideas were discriminated against when evaluated by men. The question arises as to whether findings 
would vary if the evaluations were performed in a real-life ongoing assessment scenario, as opposed to the individual isolated decision-making conditions employed in the study. Female accounts claim women's ideas are devalued. In this sense, if we assume there are no gender differences in creative outcomes (see Baer \& Kaufman 2008), we might think devaluation is about social gender interaction and not about ideas. Under lab conditions, authorship is not a decisive factor for gender bias, but undoubtedly more research is needed along the lines of gender bias.

\section{Managerial implications}

The results of the study suggest that there is no gender bias among creatives when they judge students' print ads based on name cues. Previous qualitative research states that dynamics in creative departments provoke male discrimination by gender in a wider sense. This discrimination has been expressed with different concepts in literature: boys' club, pink ghetto, glass ceiling, etc. It may also include gender bias in the idea selection (Grow et al. 2011, Windels \& Lee 2012).

However, this research indicates that this claim must be seen in context: gender bias related to idea evaluation was not found for the job entry-level positions (portfolio), although results could be different for creative women working in creative departments. If it were the case, some measures could be used to prevent evaluation bias: anonymity when presenting ideas, using external creative directors when working in networks, improving university education to support the defense of female work, etc. Likewise, a lack of gender bias in the factor of authorship is not sufficient to ensure a higher presence of females in entry-level creative job positions. Their ideas may be recommended to be included in a junior portfolio, but are they? 
More research is needed on these gender differences. Prior research suggests a lack of gender diversity in creative departments since subjectivity of creativity has a negative impact on women (Mallia 2009), however our data shows creatives would not undermine female ideas when represented by authorship. Nonetheless, the industry should question not only why creative senior women complain about gender bias at work, but also why so few women reach creative junior positions. There are many other factors at play that can impact hiring besides an impressive portfolio. We might think about lack of women in junior positions for different reasons: 1) the self-selection done by white upper middle class men (boys' club); 2) the self-limitation of young women (future mother penalty, perception of being less creative, less tendency for risk taking...); 3) a minor female student preference for creative positions, as previous research suggest (Fullerton 2009); 4) a lack of professors at university level who teach about the male environment and how to be efficient there (use of humor, social abilities with men, sensitivity management...); 5) a male professor climate at university could already reproduce the actual dynamics of advertising agencies and girls may lack a mentor who encourages them to trust and believe in their own ideas; and finally 6) portfolio based mainly on pink account ideas. If diversity sparks creativity (Govendo 2005, Basset-Jones 2005), academy could help with new lines of research to understand the lack of gender diversity at entrance level. Prevailing professional male creative criteria about ideas does not seem to be one of the reasons, at least under lab conditions. More research is needed into the impact of creative director instinct and homosociability on candidates for creative positions.

\section{LIMITATION AND FUTURE RESEARCH}


This study has several limitations, some related to the phenomenon of gender bias and others with the methodology. This is a complex topic and the methodology used can only objectify one factor of gender bias (authorship based on name cues), gender bias is not activated by the name but could be by other gender cues. A second point of criticism of this article is the use of the same product (wine) for all ads in the portfolio. A future improvement could be to consider using different products and brands. In this case, instead of assessing just one ad per author, creatives would be asked to evaluate a whole portfolio, thereby adding more realism to the evaluation process. Putting aside these considerations, the present experimental research did provide valuable information about the absence of gender discrimination in creative professionals minds when judging students work under lab conditions. A third limitation could be the limited scope of the research since it involved only 87 creatives (despite around 80 hours of phone calls), and in just one country, Spain. In the future, this research could be extended to other countries with larger markets. Future research on gender bias could lead to different scenarios. Firstly, the interviews could be performed under lab conditions (e.g. future creatives introducing their portfolios or actors playing different roles), and, in addition, through the ethnographic methodology (Cronin 2008), observing the hiring processes of juniors in creative departments. The latter could help identify if creative director instinct about the candidate and homosociability are more important than the portfolio. Secondly, replication of this study at a senior level would help to generalize findings, although at senior levels networking plays a key role (McLeod et al. 2011). Finally, researching the presence of young women in junior awards and the reasons for job preferences among advertising students would help the industry to ascertain whether creative female talent is lost at universities, as previous research claims (Grow et al. 2011), and what 
should be done to keep it. Social and cultural pressure could prevent females applying to creative departments, and self-exclusion or self-discrimination could already be present at a university level, prior to applying for positions with advertising agencies.

\section{REFERECENCES}

Alvesson, M. (1998) Gender relations and identity at work: a case study of masculinities and femininities in an advertising agency. Human Relations, 51(8), pp. 969-1005.

Amabile, T.M. (1982) Social psychology of creativity: a consensual assessment technique. Journal of Personality and Social Psychology, 43(5), pp. 997-1013.

Amabile, T.M. (1996) Creativity in Context. Boulder, CO: Westview.

Baer, J. \& Kaufman, J.C. (2008) Gender differences in creativity. The Journal of Creative Behavior, 42(2), pp. 75-105.

Baer, J., Kaufman, J.C. \& Gentile, C.A. (2004) Extension of the consensual assessment technique to nonparallel creative products. Creativity Research Journal, 16(1), pp. 113117.

Basset-Jones, N. (2005) The Paradox of Diversity Management, Creativity and Innovation. Creativity and Innovation Management, 14(2), pp. 169-175.

Bird, S.R. (1996) Welcome to the men's club: Homosociality and the maintenance of hegemonic masculinity author(s). Gender and Society, 10(2), pp. 120-132.

Bosak, J. \& Sczesny, S. (2008) Am I the right candidate? Self-ascribed fit of women and men to a leadership position. Sex Roles, 58(9-10), pp. 682-688.

Bosman, J. (2005, 5 november) Stuck at the edges of the ad game: women feel sidelined, in subtle ways. New York Times, C.1. 
Broadbridge, A. \& Simpson, R. (2011) Twenty five years on: Reflecting on the past and looking to the future in gender and management research. British Journal of Management, 22, pp. 470-483.

Broyles, S. \& Grow, J. (2008) Creative women in advertising agencies: why so few "babes in boyland"? Journal of Consumer Marketing, 25(1), pp. 4-6.

Byrne, D. (1997) An overview (and underview) of research and theory within the attraction paradigm. Journal of Social and Personal Relationships, 14(3), pp. 417-431.

Canary, D.J. \& Hause, K. (1993) Is there any reason to research sex differences in communication? Communication Quarterly, 41(2), pp. 129-144.

Chong, M. (2006) How do advertising creative directors perceive research? International Journal of Advertising, 25(3), pp. 361-380.

Correll, S., Benard, S. \& Paik, I. (2007) Getting a job: is there a motherhood penalty? American Journal of Sociology, 112 (5), pp. 1297-1338.

Cronin, A.M. (2008) Gender in the making of commercials worlds: creativity, vitalism and the practicices of marketing. Feminist Theory, 9(3), pp. 293-312.

Csikszentmihalyi, M. (1999) A systems perspective on creativity, in Sternberg, R. (ed) Handbook of Creativity, Cambridge: Cambridge University Press, pp. 313-35. Available at: www.sagepub.com/upm-data/11443_01_Henry_Ch01.pdf (accessed 15 October 2014).

Cuneo, A. \& Petrecca, L. (1997) Women target boys club of ad creatives. Advertising Age, 68(45), pp. 24-24.

Dáhlen, M., Rosengren, S. \& Törn, F. (2008) Advertising Creativity Matters, Journal of Advertising Research, 48(3), pp. 392-403. 
DiSesa, N. (2008) Seducing the boys club: uncensored tactics from a woman at the top. New York: Ballantines Books.

Eagly, A.H., Makhijani, M G. \& Klonsky, B.G. (1992) Gender and the evaluation of leaders: a meta-analysis. Psychological Bulletin, 111, pp. 3-22.

Eagly, A.H. \& Mladinic, A. (1994) Are people prejudiced against women? Some answers from research on attitudes, gender stereotypes, and judgments of competence. European Review of Social Psychology, 5(1), pp.1-35.

Estudio Infoadex de la inversión publicitaria en España (2014). Madrid: Infoadex. Available

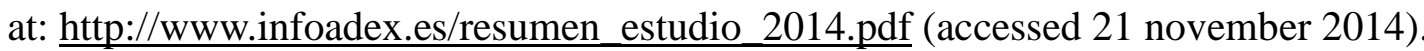

Etayo, C. \& Del Río, J. (2008) Influencia de los factores humanos sobre la creatividad en las agencias de publicidad. Zer, 25, pp. 197-219.

Fitzsimmons, E. (2008, 30 October) Feature...Asian advertising's glass ceiling. Media, 24-25. Available at: http://bit.ly/1wKiiUP (accessed 9 October 2014).

Fullerton, J., Kendrick A. \& Frazier C. (2009) Advertising student career preferences: a national survey. Special Report for the Journal of Advertising Education, 13(2), pp. 70-74.

Gelade, G.A. (1997) Creativity in conflict: the personality of the commercial creative. Journal of Genetic Psychology, 158(1), pp. 67-78.

Goldberg, P. (1968) Are women prejudiced against women? Society, 5(5), pp. 28-30.

Govendo, J. A. (2005) Workforce, diversity and corporate creativity. Handbook of Business Strategy, 6(1), pp. 213-218.

Graves, L. \& Powell, G. (1988) An investigation of sex discrimination in recruiters' evaluation of actual applicants. Journal of Applied Psychology, 73(1), pp. 20-29. 
Graves, L. \& Powell, G. (1995) The effect of sex similarity on recruiters' evaluations of actual applicants: a test of the similarity-attraction paradigm. Personnel Psychology, 48(1), pp. $85-98$.

Gregory, M.R. (2009) Inside the locker room. Male homosociability in the advertising industry. Gender, Work and Organization, 16(3), pp. 323-347.

Grow, J.M. \& Broyles, S.J. (2011) Unspoken rules of creativity game: insights to shape the next generation from top advertising creative women. Advertising \& Society Review, 12(1), pp. 1-16.

Grow, J.M. \& Deng, T. (2014) Sex segregation in advertising creative departments across the globe. Advertising \& Society Review, 14(4), pp. 1-16.

Grow, J.M., Roca, D. \& Broyles, S.J. (2011) Vanishing acts: creative women in Spain and the United States. International Journal of Advertising, 31(3), pp. 657-679.

Hackley, C. (2003) How divergent beliefs cause account team conflict. International Journal of Advertising, 22(3), pp. 313-331.

Hackley, C. \& Kover, A.J. (2007) The trouble with creatives: negotiating creative identity in advertising agencies. International Journal of Advertising, 26(1), pp. 63-78.

Halon Soto, D. \& Cole, C. (1975) Prejudice against women: a new perspective. Sex Roles, 1(4), pp. 385-393.

Hartman, J. (1988) Assessing Women in the Creative Department: What Creative Directors Think. Portland: Association for Education in Journalism and Mass Communication.

Hernández, A., Martín, M. \& Beléndez, M. (2012) La representación de la mujer en publicidad: (des)igualdad cuantitativa y cualitativa en la creatividad española [The representation of 
women in advertising: quantitative and qualitative inequality in spanish creativity]. Estudios sobre el Mensaje Periodístico, 18, pp. 521-530.

Ibarra, H. (1992) Homophily and differential returns: sex differences in network structure and access in an advertising firm. Administrative Science Quarterly, 37, pp. 422- 47.

Kanter, R. M. (1977) Some effects of proportions on group life: skewed sex ratios and responses to token women. The American Journal of Sociology, 82(5), pp. 965-990.

Kasof, J. (1993) Sex bias in the naming of stimulus persons. Psychological Bulletin, 113(1), pp.140-63.

Kaufman, J.C., Niu, W., Sexton, J.D. \& Cole, J.C. (2010) In the eye of the beholder: differences across ethnicity and gender in evaluating creative work. Journal of Applied Social Psychology, 40(2), pp. 496-511.

Kilgour, M., Sasser S. \& Koslow, S. (2013) Creativity awards; great expectations. Creativity Research Journal, 25(2), pp. 163-171.

Klein, D. (2000) Women in advertising. 10 years on. London: Institute of Practitioners in Advertising.

Knight, C. \& Thorsell, H. (2012) Mad Women: A Herstory of Advertising. Stockholm: Olika Publishing.

Koslow, S., Sasser, S. \& Riordan, E. (2003) What is creative to whom and why? Perceptions in advertising agencies. Journal of Advertising Research, 43(1), pp. 96-110.

Lázaro, P., Tena, D., Roca, D., Blanco, J.M. \& González, A. (2014) Prácticas epistémicas de la e-Research en comunicación: el caso PARC, in Romeo, E. \& Sánchez, M. (ed) Ciencias Sociales y Humanidades Digitales. Técnicas, herramientas y experiencias de e-Research e investigación en colaboración, Granada: Cuadernos Artesanos de Comunicación, pp. 
195-214. Available at: http://grinugr.org/wp-content/uploads/libro-ciencias-sociales-yhumanidades-digitales-cap8.pdf (accessed 16 November 2014).

Levenson, H., Burford, B., Bonno, B. \& Davis, L. (1975) Are women still prejudiced against women? A replication and extension of Goldberg's study. Journal of Psychology, 89(1), pp. 67-71.

Lipman-Blumen, J. (1976) Toward a homosocial theory of sex roles: an explanation of the sex segregation of social institutions. Signs, 1(3), pp. 15-31.

Mallia, K. E. (2008) New century, same story: women scarce when adweek ranks 'best spots. Journal of Advertising Education, 12(1), pp. 5-14.

Mallia, K. E. (2009) Rare birds: why so few women become ad agency creative directors. Advertising \& Society Review, 10(3). Available at: http://bit.ly/1xGr4Du (accessed 6 September 2014).

Mallia, K. E. \& Windels K. (2011) Will changing media change the world? An exploratory investigation of the impact of digital advertising on opportunities for creative women. Journal of Interactive Advertising, 11(2), pp. 30-44.

Martín, M. (2007) La mujer en la industria publicitaria. La concentración horizontal en la comunicación comercial. Anàlisi, 35, pp. 95-136.

Martín, M., Hernández, A. \& Beléndez, M. (2009) Competencias directivas en el sector publicitario. Diferencias en la percepción por generación y por sexo. Revista Latina de Comunicación Social, 12(64), pp. 228-237.

Mass, J. (2013) Mad women: the other side on Madison Avenue in the '60s and beyond. New York: Thomas Dunne Books. 
Mensa, M. \& Grow, J. M. (2015) Creative women in Peru: outliers in a machismo world. Communication \& Society, 28(2), pp. 1-18.

McLeod, C., O’Donohoe, S. \& Townley, B. (2011) Pot noodles, placements and peer regard: creative career trajectories and communities of practice in the British advertising industry. British Journal of Management, 22(1), pp. 114-131.

Michinov, E. \& Michinov, N. (2011) Social comparison orientation moderates the effects of group membership on the similarity-attraction relationship. The Journal of Social Psychology, 151(6), pp. 754-766.

Montoya, R.M., Horton, R.S. \& Kirchner, J. (2008) Is actual similarity necessary for attraction? A meta-analysis of actual and perceived similarity. Journal of Social and Personal Relationships, 25(6), pp. 889-922.

Nixon, S. (2003) Advertising Cultures: Gender, Commerce, Creativity. London: Sage Publications.

Nixon, S. \& Crewe, B. (2004) Pleasure at work? Gender, consumption and work-based identities in the creative industries. Consumption, Markets and Culture, 7(2), pp. 129-147.

Olian, J.D., Schwab, D.P. \& Haberfeld, Y. (1988) The impact of applicant gender compared to qualifications on hiring recommendations. Organizational Behavior of Human Decision Processes, 41(2), pp. 180-195.

Orphen, C. (1984) Attitude similarity, attraction, and decision-making in employment interview. The Journal of Psychology, 117(1), pp. 111-120.

Paludi, M. \& Bauer, W. (1983) Goldberg revisited: what's in an author's name. Sex Roles, 9(3), pp. 387-390.

Pool, J. (2001) Quiet never gets you anywhere. Advertising Age, 72(23), pp. 1-12. 
Pueyo, N. (2010) Sex structure of occupations in the advertising industry: where are the female ad practitioners? Observatorio Journal, 4(3), pp. 243-267.

Rand, T.M. \& Wexley, K.N. (1975) Demonstration of the effect, "similar to me" in simulated employment interviews. Psychological Reports, 36, pp. 535-544.

Roca, D., Alegre, I. \& Pueyo, N. (2011) The absence of creative women as judges in advertising awards: a case study of El Sol (1998-2008). Trípodos, 31, pp. 143-157.

Roca D., Lázaro, P., González, A., Blanco J.M. \& Tena D. (2013) Creative departments: are they for women? in $12^{\text {th }}$ International Conference on Research in Advertising. Zagreb: ICORIA.

Roca, D. \& Pueyo, N. (2011) A Gendered view on account assigment in creative departments, in $10^{\text {th }}$ International Conference on Research in Advertising. Berlin: ICORIA.

Roca, D., Tena, D. \& Lázaro, P. (2012) Is there gender bias in the assessment of advertising creativity? in $12^{\text {th }}$ International Conference on Research in Advertising. Stockholm: ICORIA.

Rosengren S., Dáhlen, M. \& Modig, E. (2013) Think Outside the Ad: Can Advertising Creativity Benefit More Than the Advertiser? Journal of Advertising Research, 42(4), pp. 320-330.

Rossiter, J.R. (2011) Measurement for the social sciences: the C-OAR-SE method and why it must replace psychometrics. New York: Springer.

Sasser S.L. \& Koslow, S. (2013) Passion, expertise, politics and support. Journal of Advertising, 41(3), pp. 5-17.

Sasser, S.L. \& Koslow, S. (2008) Desperately seeking advertising creativity: engaging an imaginative "3Ps" research agenda. Journal of Advertising, 37(4), pp. 5-19. 
Sasser, S.L., Koslow, S. \& Kilgour, M. (2013) Do clients really need highly creative advertising? Journal of Advertising Research, 53(3), pp. 297-312.

Sego, T. (1999) The effects of sex and ethnicity on evaluations of advertising job candidates: do stereotypes predict discrimination? Journal of Current Issues and Research in Advertising, 21(1), pp. 63-74.

Shao, Y., Desmarais, F. \& Weaver, K. (2014) Chinese advertising practitioners' conceptualization of gender representation. International Journal of Advertising, 33(2), pp. 329-350.

Slayden, D., Broyles, S.J. \& Kendrick, A. (1998) Content and strategy in the entry-level advertising portfolio. Journalism \& Mass Communication Educator, 53(3), pp. 13-27.

Stuhlfaut, M.W. (2011) The creative code: an organizational influence on the creative process in advertising. International Journal of Advertising, 30(2), pp. 283-304.

Swim, J., Borgida, E., Marutama, G., and Myers, D. (1989) Joan McKay versus John McKay: do gender stereotypes bias evaluation? Psychological Bulletin, 105(3), pp. 409-429.

Ward, C. (1979) Differential evaluation of male and female expertise: prejudice against women. The British Journal of Social and Clinical Psychology, 18(1), pp. 65-69.

Weisberg, L. \& Robbs, B. (1997) A study of the under representation of women in advertising agency creative departments. Chicago: Association for Education in Journalism \& Mass Communication.

Windels, K. \& Lee, W. (2012) The construction of gender and creativity in advertising creative departments. Gender in Management: An International Journal, 27 (8), pp. 502-519.

Windels, K., Lee, W. \& Yeh, Y. (2010) Does the creative boys' club begin in the classroom? Journal of Creative Education, 14(2), pp. 15-24. 


\section{Figures and tables}

Figure 1: Online random set of ads and authors (male, female, unknown gender)

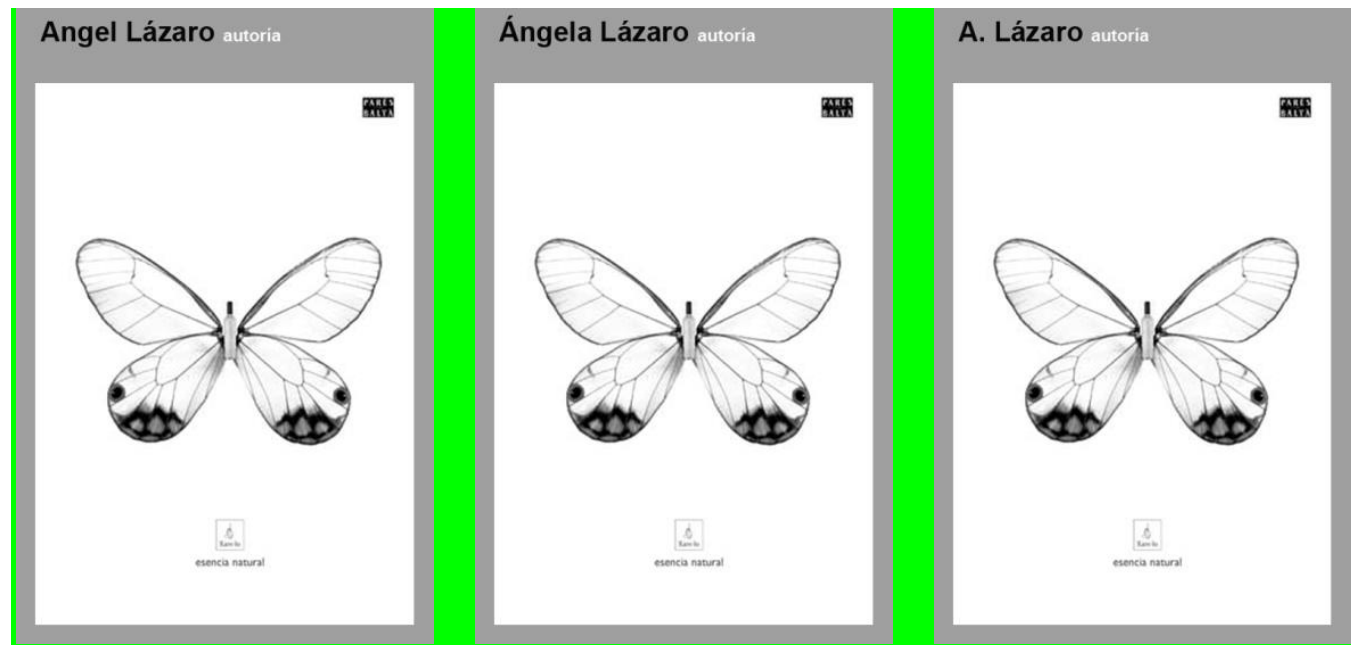

Figure 2: 27 combinations of the factorial design (3 gender authorship $\mathrm{x} 9$ ads).

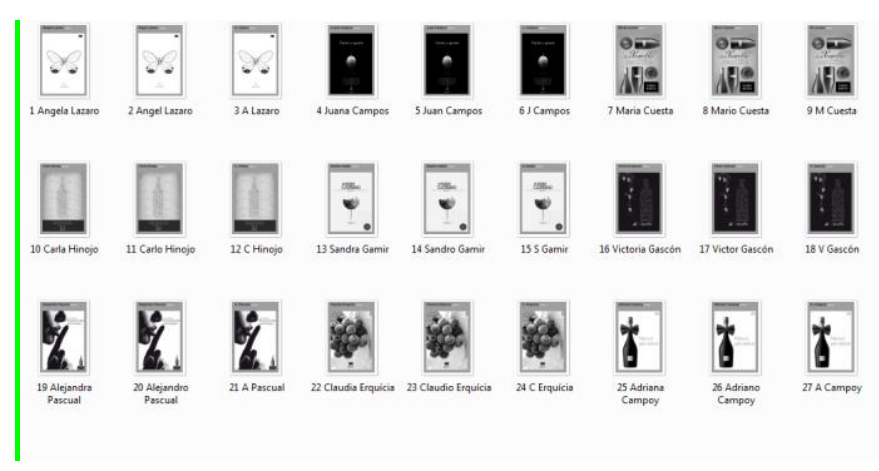

Table 1: Author name variations

\begin{tabular}{c|c|c}
\hline Female & Male & Unknown \\
\hline Angela Lázaro & Angel Lázaro & A. Lázaro \\
\hline Juana Campos & Juan Campos & J. Campos \\
\hline María Cuesta & Mario Cuesta & M. Cuesta \\
\hline Carla Hinojo & Carlo Hinojo & C. Hinojo \\
\hline Sandra Gamir & Sandro Gamir & S. Gamir \\
\hline Victoria Gascón & Víctor Gascón & V. Gascón \\
\hline Alejandra Pascual & Alejandro Pascual & A. Pascual \\
\hline Claudia Erquicia & Claudio Erquicia & C. Erquicia \\
\hline Adriana Campoy & Adriano Campoy & A. Campoy
\end{tabular}


Table 2: Estimated probabilities of recommending the selection of an ad depending on the gender who signs it (male, female, unknown gender).

\begin{tabular}{|c|c|c|c|c|c|c|c|c|c|c|}
\hline Surname & Campos & Campoy & Cuesta & Erquicia & Gamir & Gascón & Hinojo & Lázaro & Pascual & Total mean \\
\hline Male & $3.5 \%$ & $26.2 \%$ & $16.0 \%$ & $7.4 \%$ & $26.8 \%$ & $16.1 \%$ & $45.1 \%$ & $58.2 \%$ & $19.6 \%$ & $25.8 \%$ \\
\hline Female & $20.1 \%$ & $28.9 \%$ & $19.6 \%$ & $15.8 \%$ & $26.2 \%$ & $22.7 \%$ & $55.7 \%$ & $43.7 \%$ & $14.7 \%$ & $27.1 \%$ \\
\hline Unknown & $38.6 \%$ & $14.7 \%$ & $14.7 \%$ & $10.8 \%$ & $19.6 \%$ & $10.9 \%$ & $37.1 \%$ & $55.7 \%$ & $26.2 \%$ & $26.0 \%$ \\
\hline
\end{tabular}

Table 3: Judges' interval mean rating (0 to 10$)$ of creativity for each ad

\begin{tabular}{c|c|c|c|c|c|c|c|c|c|c}
\hline Surname & Campos & Campoy & Cuesta & Erquicia & Gamir & Gascón & Hinojo & Lázaro & Pascual & Total \\
\hline Male & 2.60 & 3.00 & 2.56 & 2.22 & 3.40 & 3.11 & 4.55 & 4.82 & 3.39 & 3.37 \\
\hline Female & 3.10 & 3.70 & 3.48 & 2.48 & 3.48 & 3.55 & 4.14 & 4.16 & 2.96 & 3.44 \\
\hline Unknown & 4.03 & 2.96 & 2.80 & 3.12 & 3.45 & 2.84 & 3.72 & 4.34 & 3.10 & 3.41 \\
\hline Total mean & 3.24 & 3.22 & 2.95 & 2.61 & 3.44 & 3.15 & 4.14 & 4.44 & 3.15 & 3.41 \\
\hline
\end{tabular}

Table 4: Interaction between the level of creativity and gender authorship (\% of recommended pieces)

\begin{tabular}{c|c|c} 
& \multicolumn{2}{|c}{ Level of creativity } \\
\hline Author's name & High creativity & Low creativity \\
\hline Male & $49.9 \%$ & $17.2 \%$ \\
\hline Female & $53.3 \%$ & $20.9 \%$ \\
\hline Unknown & $45.2 \%$ & $20.0 \%$ \\
\hline Mean & $49,4 \%$ & $19,3 \%$ \\
\hline
\end{tabular}

Table 5: Interaction between the author's name and the creative director's gender (\% of recommended pieces)

\begin{tabular}{c|c|c}
\multirow{2}{*}{} & \multicolumn{2}{|c}{$\begin{array}{c}\text { Gender of the } \\
\text { creative director }\end{array}$} \\
\hline Author's name & Male & Female \\
\hline Male & $21.8 \%$ & $10.2 \%$ \\
\hline Female & $26.6 \%$ & $22.2 \%$ \\
\hline Unknown & $22.2 \%$ & $25.8 \%$ \\
\hline Mean & $23.5 \%$ & $18.3 \%$ \\
\hline
\end{tabular}


